\title{
вмј Global Health Lessons learnt from implementing the Good Governance for Medicines Programme in Zimbabwe
}

Charles Chiedza Maponga, ${ }^{1}$ Takudzwa Chikwinya, ${ }^{1}$ Ropa Hove, ${ }^{2}$ Newman Madzikwa, ${ }^{3}$ Fine Mazambara, ${ }^{4}$ Stanley M Midzi, ${ }^{5}$ Forward Mudzimu, ${ }^{6}$ Misheck Ndlovu, ${ }^{3}$ William Ngirande, ${ }^{4}$ Ndanatseyi Vengesayi, ${ }^{4}$ Alison T Mhazo ${ }^{7}$
To cite: Maponga CC

Chikwinya T, Hove R, et al. Lessons learnt from implementing the Good Governance for Medicines Programme in Zimbabwe. BMJ Global Health 2022;7:e007548. doi:10.1136/ bmjgh-2021-007548

Handling editor Seye Abimbola

Received 2 October 2021 Accepted 3 December 2021

\section{Check for updates}

(c) Author(s) (or their employer(s)) 2022. Re-use permitted under CC BY-NC. No commercial re-use. See rights and permissions. Published by BMJ.

For numbered affiliations see end of article.

\section{Correspondence to}

Professor Charles Chiedza

Maponga;

cmaponga@buffalo.edu

\section{ABSTRACT}

WHO launched the Good Governance for Medicines (GGM) programme in 2004 with the aim of fighting the problem of corruption in the pharmaceutical sector. Zimbabwe adopted the GGM programme in 2015 and developed its own implementation framework (GGM-IF) in 2017 based on the WHO global guidelines and recommendations. Zimbabwe's GGM-IF emerged from; (1) home-based expertise, (2) extensive local consultations and (3) effective incorporation into existing institutions. The GGM-IF committed to implementing a focused programme over a 5-year period from 2017 to 2022 with the expressed goal of improving transparency and accountability in the pharmaceutical sector as a key enabler to improve access to medicines. Midway through its projected lifespan, some notable achievements materialised attributed to key success drivers, including mutual collaboration with the Ministry of Health and Child Care's existing Global Fund supported Quality Assurance Programme. Key challenges faced include limited funding for the programme, a shifting policy environment driven by a political transition and reorientation of priorities in the wake of the COVID-19 pandemic. This manuscript articulates 3-year operationalisation of Zimbabwe's GGM-IF highlighting the success drivers, implementation challenges and lessons learnt.

\section{INTRODUCTION}

Corruption has been associated with bad governance, weak health systems, violation of human rights and singled out as a major threat for attaining Universal Health Coverage (UHC). ${ }^{1}$ The pharmaceutical system is particularly vulnerable to inefficiencies and losses from corruption, which severely compromises access to safe, effective, good-quality medicines and undermines public interest. $^{23}$ The dimensions associated with health governance include: participation, rule of law, transparency, accountability, equity, efficiency and effectiveness, responsiveness, consensus orientation, health orientation, and decentralisation. ${ }^{4}$ WHO launched
Summary box

In 2015, Zimbabwe adopted the Good Governance for Medicines (GGM) initiative with the aim of improving transparency and accountability in the pharmaceutical sector within the context of access to medicines.

- Despite a bold commitment and high level endorsement for the initiative, several milestones contained in a 5-year national implementation framework were missed.

- The main challenges faced include limited funding, a shifting political and policy environment and a crisisladen environment geared towards alleviating urgent health problems including the COVID-19 pandemic.

- GGM actors developed innovative coping strategies to address technical challenges in the short-term while lobbying for political attention to sustain a long-term strategy.

- As fighting corruption in health systems is increasingly being recognised as an important and attractive investment in the context of Universal Health Coverage and Sustainable Development Goals, an opportunity exists to mobilise and align technica and political resources to bolster the implementation of GGM.

the Good Governance for Medicines (GGM) programme in 2004 as an innovation aimed at curbing the loss of health resources by promoting transparency and accountability. ${ }^{5}$ GGM specifically seeks to safeguard availability of medicines in participating countries by preventing corrupt practices at various levels of the medicines supply chain. By 2015, 38 countries, including Zimbabwe, had adopted the GGM concept. ${ }^{1}$ The roadmap towards achieving GGM involves a three-phase process. ${ }^{15}$ Phase I consists of a national assessment process where the level of vulnerability to corruption is determined using a WHO validated method. In phase II, a national GGM implementation framework (GGM-IF) is developed, based on findings and 
recommendations originating from phase I. A successful phase II then leads to phase III where the country adopts the framework and operationalises the GGM-IF as a component of its major strategic policy thrusts. ${ }^{1}$ Globally, the GGM has been promoted as an innovative approach to prevent corruption in the pharmaceutical sector within the context of UHC. ${ }^{6}$ Since its inception the GGM has gone under several evaluations either as a standalone initiative or as part of evaluations that focus on various initiatives aimed at improving governance in the health sector. ${ }^{78} \mathrm{~A}$ number of lessons have been documented from these evaluations, ranging from the technical prerequisites to the political determinants of its success. In the Africa region, the GGM methodology has been adapted and applied to assess governance for critical cross-cutting issues affecting the pharmaceutical sector including medicines protection and rational use. ${ }^{9}$ In general, the implementation of good governance initiatives varies despite the presence of internationally recognised principles and approaches hence it is essential for countries to recognise and identify models of good governance within the context of domestic history, culture and values. ${ }^{10}$

\section{ZIMBABWE'S GGM PROGRAMME APPROACH Involvement in the GGM programme}

In 2015, Zimbabwe's GGM programme was spearheaded by the Ministry of Health and Child Care's Directorate of Pharmacy Services (MoHCC-DPS) in partnership with the WHO Country Office. The phase I, national assessment was conducted by research consultants from the University of Zimbabwe Department of Pharmacy and Pharmaceutical Sciences' Centre of Excellence for Pharmaceutical Innovation (COE-PI). ${ }^{11}$ Key findings from the widely consultative national assessment resulted in recommendations to proceed to phase II whose goal was to develop the GGM-IF.

\section{Development of the GGM-IF}

The same COE-PI team which conducted Phase I was appointed by the WHO Country Office as Consultants to facilitate the development of the country's GGM-IF. A WHO-funded consultative workshop was organised for key stakeholders from the academic, public and private sectors, thus ensuring as much inclusion of local experts as possible. Held on 22 June 2017, the workshop included a resource expert from the WHO Headquarters in Geneva, Switzerland. The WHO GGM expert shared experiences from other GGM participating countries and assisted in reviewing the findings and recommendations from phase I. The consultative workshop engaged the participants in an exercise to identify Zimbabwe's GGM goal and priority areas. The COE-PI consultants then took over the process and completed it with a consumerbased study as well as a series of consultations with individual key stakeholders. The GGM-IF was then presented for approval at another stakeholders' workshop held on 22 September 2017.

\section{Key features of the GGM-IF}

The expressed goal of Zimbabwe's GGM-IF was, 'to improve public trust and confidence in Zimbabwe's medicines supply system through transparent, accountable, equitable and sustainable provision of medicines.' This goal would be met by adopting WHO's revised GGM approach which emphasised two strategies for improving governance, namely the discipline-based as well as valuesbased system.

\section{Execution of the GGM-IF}

Continuing from Phase I and II, the MoHCC-DPS assigned the University of Zimbabwe's Department of Pharmacy and Pharmaceutical Sciences to operationalise the GGM-IF through the COE-PI. This ensured retention of local expertise throughout. The Framework committed to executing a focused programme over a 5-year period from 2017 to 2022 with the expectation of receiving dedicated funding as had happened for phases I and II. However, in November 2017, there was a political downturn, which resulted in the change of government and reprioritisation of public sector programmes. Subsequently the GGM-IF did not receive the anticipated dedicated funding support even though commitment to its implementation was already in place.

\section{'Dual Strategy' implementation}

Figure 1 shows how the COE-PI has utilised a 'dual strategy' by integrating the GGM programme with the MoHCC existing Global Fund supported Quality Assurance Programme (QAP), which is being coordinated by the Medicines Control Authority of Zimbabwe (MCAZ). The Global Fund for HIV/AIDS, tuberculosis and malaria has supported the QAP since 2017. Its mandate is to improve quality of pharmaceutical service delivery by building the capacities of the MoHCC, MCAZ, the local schools of pharmacy and the National Pharmaceutical Company (NatPharm). Being the national pharmaceutical regulatory agency, the MCAZ is perfectly placed to anchor both the discipline-based and the value-based strategic goals. The schools of pharmacy mostly promoted the value-based system through training and advocacy.

\section{NOTABLE OUTPUTS FROM ZIMBABWE'S GGM PROGRAMME AND CROSS CUTTING INNOVATIONS TO SUSTAIN IT \\ Strengthening academic-public-private sector partnerships}

The initial 3 years of operationalisation of the GGM-IF, produced key outputs shown in table 1 above.

The first output was the catalytic enhancement effect that the programme had on the COE-PI. COE-PI had been designed to strengthen academic-public-private sector partnerships. Its involvement in the GGM programme strategically positioned the contribution of the COE-PI towards ensuring equitable and sustainable access to good quality and effective medicines as shown 


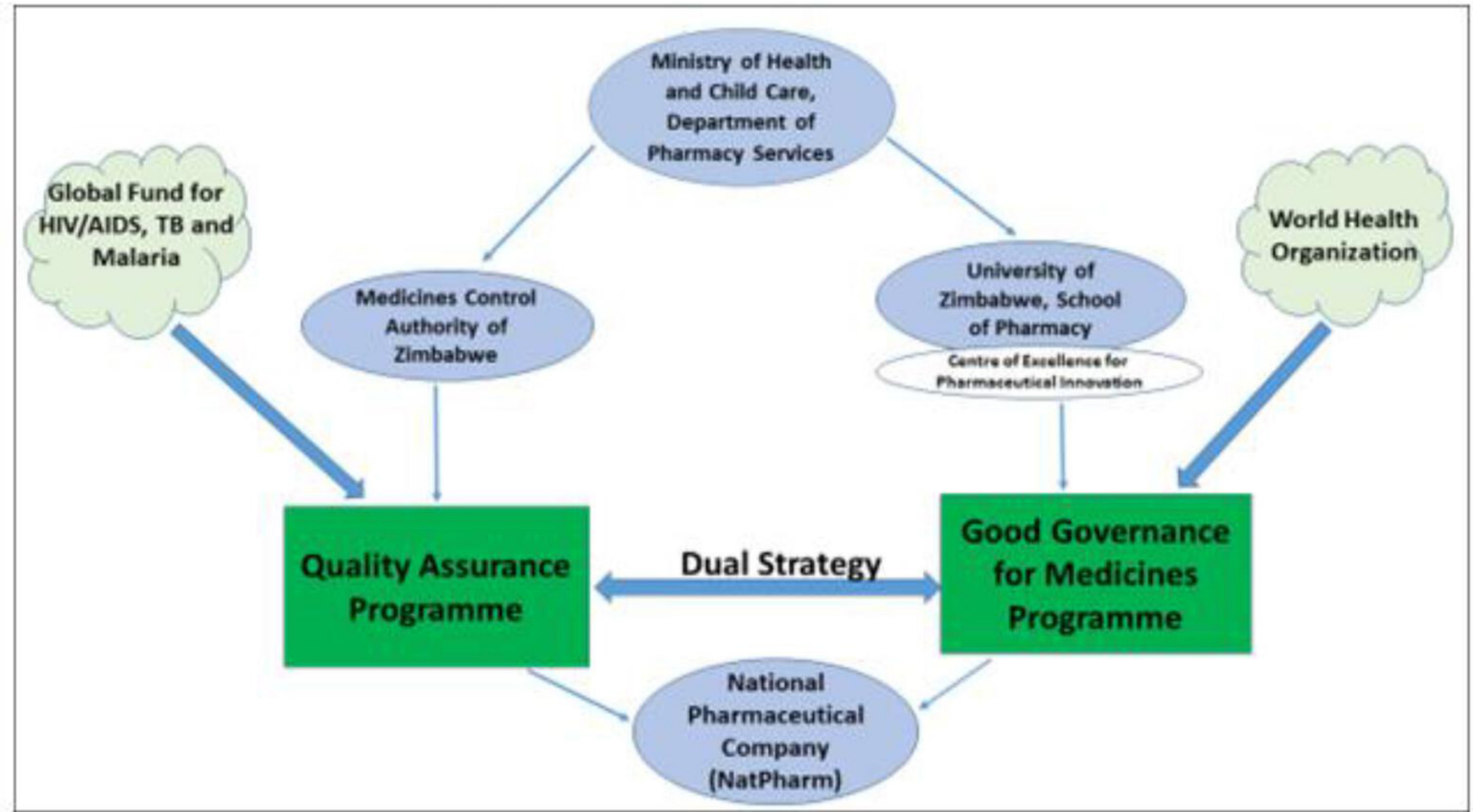

Figure 1 Zimbabwe's GGM Framework GGM, Good Governance for Medicines; TB, tuberculosis.

in figure 2. Operationalisation of the GGM-IF through the dual strategy has achieved several noble outcomes shown in figure 2, although with limited resources. COE-PI also operates the University of Zimbabwe International Pharmacology Specialty Laboratory which carries out pharmacovigilance studies in collaboration with the MCAZ. ${ }^{12}$ Through its participation in QAP planning and coordination meetings, COE-PI has developed a training programme for traditional health practitioners to improve the quality of complimentary medicines. In collaboration with NatPharm, plans are underway to introduce unmanned aerial vehicles (drone technology) for efficient delivery of antidotes, vaccines, and HIV and COVID-19 test kits to remote areas of the country.

\section{Incorporation of GGM into pharmacy curricula and motivation for the establishment of district drug information centres}

A sustainable value-based programme that incorporates issues of governance and ethical practice has been incorporated into the undergraduate and postgraduate curriculum for pharmaceutical personnel at the University of Zimbabwe. Since 2017, training components incorporated into the Clinical Pharmacy course that is undertaken by undergraduate pharmacy students in their third year. The course equips students with skills in providing cognitive services in addition to regular dispensing duties. The course incorporates, 'How to set up district drug information centres', and practical sessions on, 'Live Query' answering. Three student streams have been taught and two of them have already graduated. Soon after introducing the course, COE-PI began to motivate for setting up of drug information centres at district level throughout the country. As such, there is a readily available pool of qualified personnel that can run these drug information centres in all districts throughout the country. The postgraduate masters in applied pharmaceutical sciences includes; pharmaceutical formulation, manufacturing, and pharmaceutical regulatory affairs.

\section{Linkages with emerging priorities in the therapeutic and policy environment}

With the increasing demand for complementary and alternative medicine, the need for clearer understanding of herbal therapies has increased. ${ }^{13}$ Advancement of advocacy for herbal therapies thrives through formation of the Natural Therapist Council of Zimbabwe (NTCZ). COE-PI has been a key participant in the NTCZ board. This promotes the progress of GGM implementation while raising awareness on the GGM initiative throughout the health delivery system in the country.

\section{Creation and establishment of the Parliamentary Pharmaceutical Caucus}

To facilitate political petitioning, COE-PI conceptualised and advocated for the establishment of a Parliamentary Pharmaceutical Caucus (PPC). Among other aims, the PPC terms of reference include; (1) campaigning for transparency in the medicines supply chain at different levels of healthcare, (2) advocating for equal access to essential medicines as part of health service provision and (3) ensuring a culture of regulatory compliance within the pharmaceutical sector. COE-PI serves as the secretariat which manages the day-to-day affairs of the PPC. So far, the PPC members have led the Parliamentary 
Table 1 Notable outputs of Zimbabwe's Good Governance for Medicines (GGM) programme

\begin{tabular}{|c|c|c|}
\hline Outputs & Purpose of outputs & Outcomes of the outputs \\
\hline $\begin{array}{l}\text { 1. Activation of the } \\
\text { newly established } \\
\text { Centre of Excellence for } \\
\text { Pharmaceutical Innovation }\end{array}$ & $\begin{array}{l}\text { To strengthen academic-public- } \\
\text { private pharmaceutical sector } \\
\text { collaboration. } \\
\text { To ensure equitable and sustainable } \\
\text { access to good quality and effective } \\
\text { medicines. } \\
\text { To provide medicines in a } \\
\text { transparent and accountable } \\
\text { manner. } \\
\text { To implement the dual strategy } \\
\text { combining the efforts of Ministry's } \\
\text { existing Quality Assurance } \\
\text { Programme (QAP) and the GGM } \\
\text { programme. }\end{array}$ & $\begin{array}{l}\text { Funding was secured from private pharmaceutical } \\
\text { companies to support the GGM activities. } \\
\text { Setting up a PPC and serving as its secretariat. } \\
\text { Driving the GGM implementation strategy although } \\
\text { with limited resources. } \\
\text { Establishing the UZ-IPSL to support } \\
\text { pharmacovigilance activities. } \\
\text { Discussion on introducing unmanned aerial vehicle } \\
\text { technology at NatPharm for delivery of poison } \\
\text { antidotes, vaccines, HIV and COVID-19 test kits. } \\
\text { Developing a training programme for traditional health } \\
\text { practitioners to improve the quality of complimentary } \\
\text { medicines. } \\
\text { Participating in the QAP planning and coordination } \\
\text { meetings. }\end{array}$ \\
\hline $\begin{array}{l}\text { 2. Incorporation of GGM } \\
\text { into undergraduate and } \\
\text { postgraduate pharmacy } \\
\text { curricula } \\
\text { a. Motivation for } \\
\text { the establishment } \\
\text { of District Drug } \\
\text { Information Centres }\end{array}$ & $\begin{array}{l}\text { To incorporate issues of good } \\
\text { governance and ethical practice in } \\
\text { the training of pharmacy personnel } \\
\text { thereby ensuring a sustainable } \\
\text { values-based programme. } \\
\text { To provide practical training for } \\
\text { undergraduate pharmacy students } \\
\text { on how to set up drug information } \\
\text { centres at district level. }\end{array}$ & $\begin{array}{l}\text { Promoting transparent and ethical behaviour during } \\
\text { the training of pharmacy personnel. } \\
\text { Promoting GGM among postgraduate masters } \\
\text { students in applied pharmaceutical sciences } \\
\text { programme which includes; pharmaceutical } \\
\text { formulation, manufacturing and pharmaceutical } \\
\text { regulatory affairs. } \\
\text { Since 2017, Part III Pharmacy Drug Information } \\
\text { course incorporated, 'How to set up district drug } \\
\text { information centres', and practical sessions on, 'Live } \\
\text { Query' answering. }\end{array}$ \\
\hline $\begin{array}{l}\text { 3. Concept development } \\
\text { and establishment } \\
\text { of a Parliamentary } \\
\text { Pharmaceutical Caucus } \\
\text { (PPC) }\end{array}$ & $\begin{array}{l}\text { To assemble a caucus of health } \\
\text { professionals whose terms of } \\
\text { reference include; } \\
\text { - Campaign for transparency in the } \\
\text { medicines supply chain, GGM at } \\
\text { different levels of healthcare. } \\
\text { - Advocate for equal access to } \\
\text { essential medicines as part of } \\
\text { health service provision. } \\
\text { - Ensure and promote a culture of } \\
\text { regulatory compliance within the } \\
\text { pharmaceutical sector. }\end{array}$ & $\begin{array}{l}\text { Parliamentary Pharmaceutical sector Assessment } \\
\text { presented and debated the House of Assembly and } \\
\text { published in HANSARD. } \\
\text { Unfreezing of district level pharmacist posts in the } \\
\text { Ministry of Health by } 2019 \text {. } \\
\text { Official launch of the PPC in } 2021 \text {. } \\
\text { Formation of the Natural Therapist Council of } \\
\text { Zimbabwe with representation from and participation } \\
\text { of the GGM secretariat. }\end{array}$ \\
\hline
\end{tabular}

NatPharm, National Pharmaceutical Company; UZ-IPSL, University of Zimbabwe International Pharmacology Specialty Laboratory.

Portfolio Committee on Health and Child Care in conducting an assessment of the pharmaceutical sector which produced a report. The report was subsequently debated in the National Assembly to come up with a number of resolutions which include; recommendation for the unfreezing of district level pharmacists posts in the MoHCC by the end of 2019. ${ }^{14}$ Recommendations were also made for comprehensive capacity building at the NatPharm.

\section{GGM CHALLENGES AND STRATEGIES TO ADDRESS THEM}

Among the originally planned activities, there are several missed targets as shown in the Gantt chart presented in table 2, which was prepared as part of the GGM-IF. These include lack of funding, limited engagement of stakeholders and a shifting policy and political environment.
The major missed target was the failure to secure development partner funding. This occurred due to the political transition following the change-over of government in 2017 and the subsequent emergence of COVID-19 which resulted in the reprioritisation of MoHCC programmes. Fresh negotiations between the Government and its development partners resulted in the exclusion of funding for the GGM Programme. In response, GGM activities were mapped according to funding needs followed by a stakeholder analysis to identify potential funders outside the government and the traditional developmental funders. Following a strategic analysis of the resource needs and the potential attractiveness of GGM activities among stakeholders, funding was secured from a private pharmaceutical wholesaler to revitalise some key activities. A key factor in promoting GGM is availability of political 


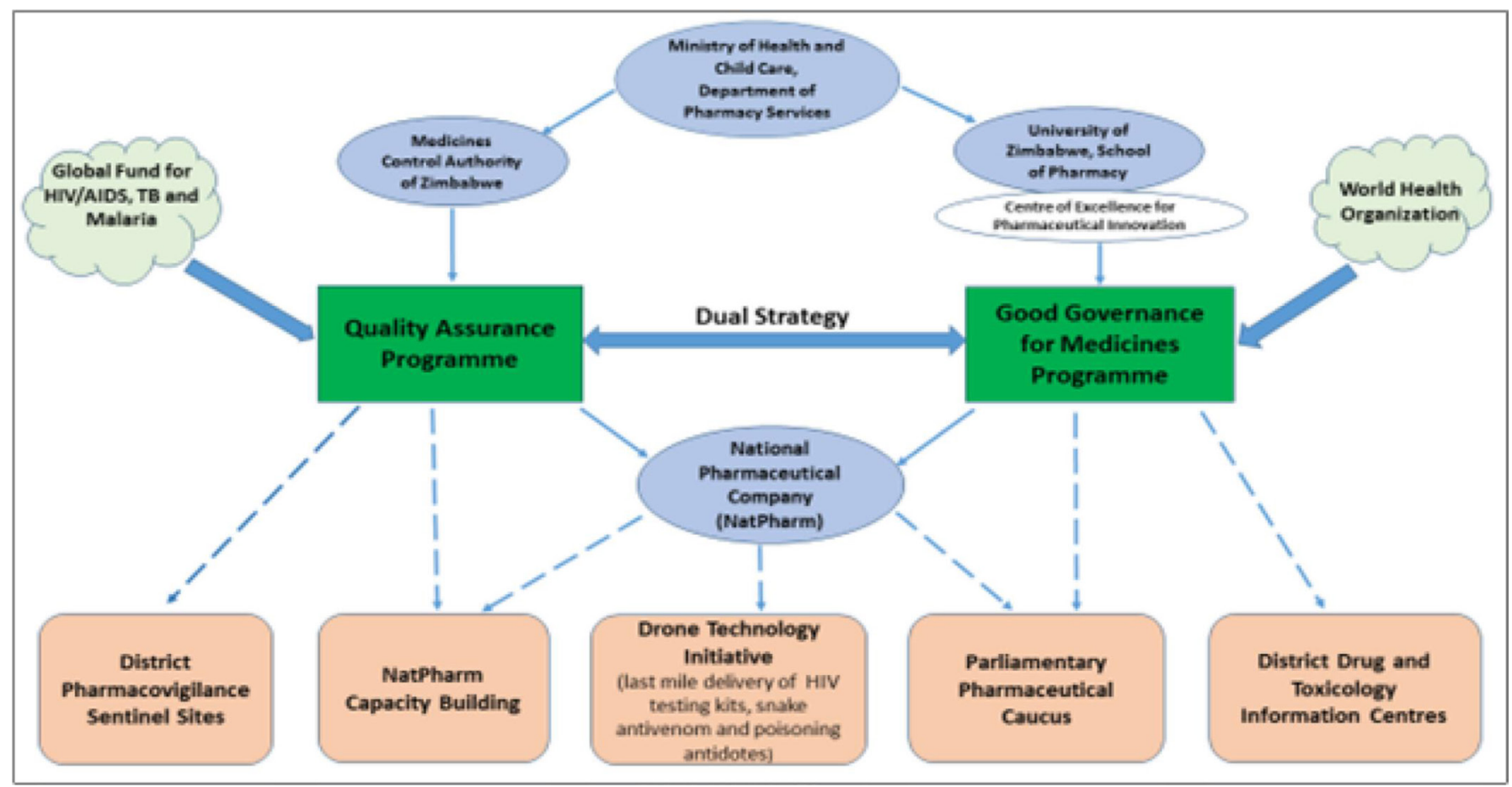

Figure 2 Zimbabwe's GGM framework and notable outputs. GGM, Good Governance for Medicines; TB, tuberculosis.

will. At the macro level, there was a delay in political petitioning between from September 2017 to September 2018. Despite the delay, GGM actors maintained a critical awareness of the sociopolitical environment and its influence on GGM which culminated in the creation of the
PPC through collaborative lobbying with newly elected parliamentarians from the pharmacy profession.

The WHO recommends using both disciplinebased and value-based approaches in implementing GGM. Zimbabwe's GGM-IF intended to achieve this by

\begin{tabular}{|c|c|c|c|c|c|c|c|c|c|c|}
\hline Date & $\begin{array}{l}\text { September } \\
2017\end{array}$ & $\begin{array}{l}\text { March } \\
2018\end{array}$ & $\begin{array}{l}\text { September } \\
2018\end{array}$ & $\begin{array}{l}\text { March } \\
2019\end{array}$ & $\begin{array}{l}\text { September } \\
2019\end{array}$ & $\begin{array}{l}\text { March } \\
2020\end{array}$ & $\begin{array}{l}\text { September } \\
2020\end{array}$ & $\begin{array}{l}\text { March } \\
2021\end{array}$ & $\begin{array}{l}\text { September } \\
2021\end{array}$ & $\begin{array}{l}\text { March } \\
2022\end{array}$ \\
\hline \multicolumn{11}{|l|}{ Activities } \\
\hline $\begin{array}{l}\text { Formation and approval } \\
\text { of steering committee }\end{array}$ & $\sqrt{ }$ & & & & & & & & & \\
\hline $\begin{array}{l}\text { Setting up of GGM } \\
\text { office at UZ COE-PI }\end{array}$ & $\sqrt{ }$ & & & & & & & & & \\
\hline $\begin{array}{l}\text { Securing development } \\
\text { partner funding }\end{array}$ & $x$ & $x$ & $x$ & $x$ & $x$ & $x$ & $x$ & & & \\
\hline $\begin{array}{l}\text { Incorporation of GGM } \\
\text { course into research and } \\
\text { teaching curricula }\end{array}$ & & & * & * & * & * & * & & & \\
\hline $\begin{array}{l}\text { Formation of } \\
\text { collaborative } \\
\text { agreements }\end{array}$ & & & * & * & * & * & * & & & \\
\hline $\begin{array}{l}\text { Petitioning for political } \\
\text { and policy support }\end{array}$ & $x$ & $x$ & $x$ & $\sqrt{ }$ & $\sqrt{ }$ & $\sqrt{ }$ & $\sqrt{ }$ & & & \\
\hline Advocacy & $x$ & $x$ & * & * & * & * & * & & & \\
\hline $\begin{array}{l}\text { Monitoring and } \\
\text { evaluation }\end{array}$ & * & * & * & * & * & * & * & & & \\
\hline $\begin{array}{l}\text { Evaluation/national } \\
\text { assessment }\end{array}$ & & & & & $\sqrt{ }$ & $\sqrt{ }$ & * & & & \\
\hline
\end{tabular}

$\checkmark$ Activity accomplished.

$X$ Activity NOT accomplished.

${ }^{*}$ Activity partially accomplished.

COE-PI, Centre of Excellence for Pharmaceutical Innovation; GGM, Good Governance for Medicines; UZ, University of Zimbabwe. 
combining the efforts of MCAZ and other regulatory agencies such as the Zimbabwe Republic Police, the Department of Customs and Excise and the Zimbabwe Anti-Corruption Commission to provide adequate workforce for inspections and other issues pertaining regulation of medicines. So far, while the MCAZ is closely involved, other agencies such as the Health Professions Authority, and the national law-enforcement agents are still to be included. Advocacy, monitoring and evaluation were also delayed due to policy changes at the MoHCC. These targets are considered as partially achieved since they were only carried out using limited internal COE-PI resources. Incorporation of GGM into research and teaching curricula is considered partially implemented because it has so far only benefited the University of Zimbabwe's pharmacy students. GGM should ideally be included in pharmacy programmes at other institutions and other health professions.

\section{LESSONS LEARNT}

Overall, the key lesson learnt from GGM implementation in Zimbabwe is that it requires a multi-sectoral approach and an appreciation of the critical role that politics plays in public health affairs. As documented elsewhere, clearer understanding of the political dimensions of health policy by public health professionals in government, advocacy groups, and research organisations is necessary for designing more effective policies and programmes. ${ }^{15}$ GGM in Zimbabwe started with implementation of aspects within the predominant remit and mandate of technocrats such as curriculum design and quality assurance before approaching state level institutions such as parliament to seek audience for wider reforms. Keyspecific lessons learnt include (1) the importance of academic-public-private partnerships (PPPs), (2) policy consciousness to generate context-specific innovations to attain quick wins and (3) the importance of political lobbying to generate attention among national leaders.

Regarding PPPs, the dual strategy of combining QAP and GGM programmes strengthened academicPPPs and collaborations. Such a partnership is not a novel concept, commonly observed in developed countries and has been linked to supporting SDGs, implementation of primary healthcare, effective regulation of medicines and pharmaceutical innovation at global level. ${ }^{16-20}$ The strengthened PPPs in Zimbabwe facilitated the mobilisation of funding from the private sector when the government and traditional development funders could not commit resource to GGM. Another key lesson learnt is that while GGM requires increasing amounts of funding throughout its lifespan, generation of context-specific innovations facilitates attainment of low-cost quick wins to lay the foundation for long-term implementation. In this vein, Zimbabwe has demonstrated adequate capability to implement its GGM-IF, with success in training, QA and advocacy with limited funding. This was done through leveraging existing relationships within the dual strategy and taking advantage of the COE-PI's reputation in teaching by incorporating GGM components into the pharmacy curriculum to reinforce the value based strategy. At policy level, advocacy was facilitated by the positioning of GGM within the context of emerging therapeutic developments under the newly established Natural Therapists Council of Zimbabwe (NTCZ) to resonate with the evolving policy landscape. However, financial support is vital for the continuation and further rolling out GGM activities. Another key lesson learnt is the importance of the political dimensions of the GGM to enhance political feasibility and sustainability. Although the process was slow and typical of institutional change, strategic lobbying between the GGM policy community and the newly elected pharmacist parliamentarians culminated in the positioning of GGM within the broader mandate of national pharmaceutical development being championed by the PPC.

\section{RECOMMENDATIONS}

The missed targets observed in Zimbabwe's GGM programme were mostly due to changes in government priorities as well as the disruptive effects of the COVID-19 pandemic. However, the bottom-line issue was the lack of dedicated funding to support the GGM-IF. In this regard, the overall recommendation is that government and its development partners should provide funding to drive the country's GGM programme. Such dedicated funding would not only ensure equitable and sustainable access to good quality and effective medicines, but also provide medicines in a transparent and accountable manner. Details of the challenges faced in the operationalisation of Zimbabwe's GGM programme and the respectively suggested solutions are shown in table 3 . In addition to securing dedicated funding support for the GGM-IF activity, other key recommendations include involvement of all necessary stakeholders, pursuing partner collaborations, introduction of GGM into the curricula at other health professional training institutions, adoption of digital platforms and GS1 standards to improve efficiency, as well as creating an advocacy team for GGM.

Given that governance for medicines lies at the interface of politics, public health and pharmaceutical science, further research is needed to understand how an interaction of these factors influenced the implementation of GGM in Zimbabwe.

\section{CONCLUSION}

After 3years of implementation, the GGM programme has recorded some notable achievements although with limited resources and the changeover of Governments in 2017. In summary, the key success factors of the GGM-IF 
Table 3 GGM challenges faced and suggested solutions

\section{GGM framework planned activity Challenge}

Formation and approval of GGM Steering Committee

Engagement of existing regulatory agents including; the Medicines Control Authority of Zimbabwe (MCAZ), Health Professions Authority (HPA), and national law-enforcement agents

Securing development partner funding to support the GGM implementation
Steering Committee was formed and approved but it failed to meet, due to the lack of dedicated funding to support GGM Steering Committee meetings.

Dual Strategy only enabled engagement of MCAZ through the Quality Assurance Programme which did not include HPA and law-enforcement agents.

\section{How to address them}

Secure dedicated funding support for this activity.

Inclusion of all necessary stakeholders will be possible if dedicated funding to support this endeavour is secured for that purpose.

With the new dispensation coming in in Pursue partner collaborations to November 2017, funding mechanisms and secure funding for GGM activities. priorities appeared to change resulting less effort being put into securing partner support for GGM.

Incorporation of GGM into curricula for health professions students (pharmacy, pharmacy technicians, medicine, nursing)

Limited funding within COE-PI only allowed for the GGM host (University of Zimbabwe)'s pharmacy students but left out other universities and other health professions students.

Formation of collaborative agreements Limited funding for COE-PI, to influence change in government policies. Slowing down of activities due to the COVID-19 pandemic.
Secure dedicated funding for the introduction of GGM into the curricula at other health professional training institutions.

\section{Secure dedicated funding to cater for} COE-PI projects.

Aggressively adopt and improve online systems to fast track progress made on all activities.

Petitioning for political and policy support Activities slowed down by limited funding and recently the COVID-19 pandemic.

\begin{tabular}{ll} 
Advocacy & $\begin{array}{l}\text { Limited funding, inflation due to } \\
\text { unstable currency, COVID-19 and shift } \\
\text { in government priorities with the new } \\
\text { dispensation. }\end{array}$ \\
$\begin{array}{ll}\text { Monitoring and evaluation system linked } \\
\text { to the existing one within the Ministry of } \\
\text { Health and Child Care }\end{array}$ & $\begin{array}{l}\text { Changes in government priorities resulting } \\
\text { in limited funding support for GGM } \\
\text { activities. }\end{array}$ \\
\hline $\begin{array}{l}\text { Increase traceability of medicines within } \\
\text { the supply chain }\end{array}$ & $\begin{array}{l}\text { Reported leakage of medicines from the } \\
\text { public to the private sector } \\
\text { Identification of falsified medicines within } \\
\text { the system not easily identified. }\end{array}$ \\
\hline
\end{tabular}

Need to aggressively adopt and improve online systems to fast track progress made on all activities.

Inclusion of an advocacy team in the government decision making committees to push for pharmaceutical agendas.

Create an advocacy team comprising of pharmacists in the Ministry of Health and Child Care decision making board. Introduce GS1 standards with the country supply chain systems for medicines.

GGM, Good Governance for Medicines.

are that it emerged from home-based expertise, extensive local consultations and effective incorporation into existing institutions which created the unique 'dual strategy' feature of the GGM-IF and a platform for strengthened academicpublic-private sector collaboration. However, it remains uncertain whether the intended goal and outcomes will be achieved over the set 5-year period particularly in the face of unpredictable funding and possible fluctuations in prioritisation with shifting political and policy priorities. An alignment of technical and political priorities is needed to bolster the much-needed implementation of the GGM initiative in Zimbabwe.

\section{Author affiliations}

${ }^{1}$ Pharmacy and Pharmaceutical Sciences, University of Zimbabwe, Harare, Zimbabwe
${ }^{2}$ Independent Researcher, Harare, Zimbabwe

${ }^{3}$ Ministry of Health and Child Care-Directorate of Pharmacy Services, Ministry of Health and Child Care, Harare, Zimbabwe

${ }^{4}$ Department of Pharmacy and Pharmaceutical Sciences, Centre of Excellence for Pharmaceutical Innovation (COE-PI), University of Zimbabwe, Harare, Zimbabwe ${ }^{5}$ World Health Organization Zimbabwe Country Office, World Health Organization Regional Office for Africa, Brazzaville, Zimbabwe

${ }^{6}$ United Nations Development Programme (UNDP), Zimbabwe Global Fund Project, United Nations Development Programme Zimbabwe, Harare, Zimbabwe

${ }^{7}$ Ministry of Health, Ministry of Health Malawi, Lilongwe, Malawi

Twitter Newman Madzikwa @nmadzikwa

Contributors CCM led the design, conduct and analyses of the manuscript. TC drafted the initial version of the manuscript. All the authors made a substantial contribution to the structure and content of the manuscript.

Funding The authors have not declared a specific grant for this research from any funding agency in the public, commercial or not-for-profit sectors. 
Competing interests None declared.

Patient consent for publication Not applicable.

Provenance and peer review Not commissioned; externally peer reviewed.

Open access This is an open access article distributed in accordance with the Creative Commons Attribution Non Commercial (CC BY-NC 4.0) license, which permits others to distribute, remix, adapt, build upon this work non-commercially, and license their derivative works on different terms, provided the original work is properly cited, appropriate credit is given, any changes made indicated, and the use is non-commercial. See: http://creativecommons.org/licenses/by-nc/4.0/.

\section{REFERENCES}

1 Vian T. Anti-corruption, transparency and accountability in health: concepts, frameworks, and approaches. Glob Health Action 2020;13:1694744.

2 Management Sciences for Health. Strengthening pharmaceutical systems (SPS). pharmaceuticals and the public interest: the importance of good governance. management sciences for health. Available: www.msh.org > sites > default > files > sps_governance_ pub_final_2011_0[Accessed July 1, 2021].

3 Paschke A, Dimancesco D, Vian T, et al. Increasing transparency and accountability in national pharmaceutical systems. Bull World Health Organ 2018;96:782-91.

4 Jafari F, HajiNabi K, Jahangiri K, et al. Good governance in the health system: a qualitative study. International Transaction Journal of Engineering, Management, \& Applied Sciences \& Technologies 2019;8:1127-41.

5 World Health Organization. Good governance for medicines: model framework, updated version 2014. World Health organization. Available: apps.who.int , iris , handle [Accessed 16 June, 2021].

6 Baghdadi-Sabeti G, Serhan F. Who good governance for medicines programme: an innovative approach to prevent corruption in the pharmaceutical sector. World Health organization. Available: www. who.int , healthsystems , topics , financing , healthreport [Accessed 14 June, 2021].

7 Kohler JC, Ovtcharenko N. Good governance for medicines initiatives: exploring lessons learned [Accessed 16 Jun 2021].
8 Martin J, Ollier L. Evaluation of the good governance for medicines programme. (2004- 2012): brief summary of findings. Available: background:white">https://www.who.int , [Accessed 14 June 2021].

9 McLean M, Kohler JC, Edwards D. Assessing national governance of medicine promotion: an exploratory study in Ghana to trial a structured set of indicators. J Pharm Policy Pract 2019;12:26.

10 Jafari F, HajiNabi K, Jahangiri K. Explaining the indicators of good governance in the health system. Revista Publicando 2018;5:965-86.

11 World Health Organization. Assessing transparency in the pharmaceutical sector in pursuit of promoting good governance for medicines in Zimbabwe. Harare Zimbabwe: World Health Organization Zimbabwe Country Office, 2016.

12 Mtisi TJ, Maponga C, Monera-Penduka TG, et al. Strategic establishment of an international pharmacology specialty laboratory in a resource-limited setting. Afr J Lab Med 2018;7:659.

13 Welz AN, Emberger-Klein A, Menrad K. Why people use herbal medicine: insights from a focus-group study in Germany. BMC Complement Altern Med 2018;18:92.

14 Parliament. Second report of the portfolio Committee on health and child care on the state of medicines and drugs supply in the public health institutions of Zimbabwe. Available: www.parlzim.gov.zw , national-assembly-hansard, national-assembly-han. [Accessed 16 Jun 2021].

15 Oliver TR. The politics of public health policy. Annu Rev Public Health 2006;27:195-233.

16 de Vrueh RLA, Crommelin DJA. Reflections on the future of pharmaceutical public-private partnerships: from input to impact. Pharm Res 2017;34:1985-99.

17 Stafford-Smith M, Griggs D, Gaffney O, et al. Integration: the key to implementing the sustainable development goals. Sustain Sci 2017:12:911-9.

18 Joudyian N, Doshmangir L, Mahdavi M, et al. Public-private partnerships in primary health care: a scoping review. BMC Health Serv Res 2021;21:4.

19 Kumaranayake L, Mujinja P, Hongoro C, et al. How do countries regulate the health sector? Evidence from Tanzania and Zimbabwe. Health Policy Plan 2000:15:357-67.

20 Berger M, Murugi J, Buch E. Strengthening pharmaceutical innovation in Africa. Council on Health Research for Development (COHRED); New Partnership for Africa's Development (NEPAD). Available: www.unido.org , sites > default , files , 2016-01 , COHREDNEPAD Str. 